\title{
FERRAMENTA DE APOIO AO DESENVOLVIMENTO COGNITIVO DE DEFICIENTES
}

Bruno Cavalcante Guidetti-bruno.cg3@puccampinas.edu.br

Faculdade de Engenharia Mecânica

Amilton da Costa Lamas - amilton@puc-campinas.edu.br

Faculdade de Engenharia Elétrica

Pontifícia Universidade Católica de Campinas,

Rua Professor Dr. Euryclides de Jesus Zerbini, 1516

13087-571 - Campinas - SP

Resumo: Deficientes visuais com baixa visão e alguns deficientes físicos com paralisia cerebral precisam de treinamento cognitivo para desenvolverem a capacidade de mobilidade autônoma. Neste artigo, motivado pelo objetivo principal de promover a inclusão e autonomia de deficientes, descreve-se a idealização, construção e a validação da prova de conceito de uma ferramenta de apoio ao desenvolvimento visual e cognitivo de deficientes. O trabalho foi realizado num formato colaborativo junto à duas instituições campineiras que prestam serviços às pessoas com alguma deficiência visual, motora elou cognitiva, o Centro Cultural Louis Braille de Campinas e a Therapies Serviços de Fisioterapia. A prova de conceito é uma ferramenta assistiva, baseada em conceitos de gamificação, no formato de um jogo de tabuleiro formado por 15 células de cores e intensidade de luz ajustáveis. O princípio básico do jogo é a replicação de sequência de cores e posições programáveis. A ferramenta é resultado da problematização das dificuldades e necessidades cognitivas dos deficientes realizada junto aos técnicos especialistas e assistidos das duas instituições parceiras. O método de trabalho colaborativo, utilizado em todas as fases do projeto, garante que o resultado final atende à todas as especificações, funcionais e não funcionais, esperadas pelo público alvo.

Palavras-chave: deficiência. desenvolvimento cognitivo. extensão universitária. paralisia cerebral. trabalho colaborativo.

\section{INTRODUÇÃO}

No Brasil existem mais de 45,6 milhões de pessoas com alguma deficiência, entre elas 6,5 milhões possuem deficiência visual, sendo que destas 583 mil são cegas e 6 milhões possuem baixa visão, ou seja, tem algum tipo de comprometimento visual. Dentre o conjunto de deficientes identifica-se os casos de comprometimento cognitivo e consequente limitações de mobilidade decorrentes de paralisia cerebral em crianças. Este conjunto de deficientes foi incluído no número total de deficientes no Brasil segundo o censo realizado pelo IBGE (Instituto Brasileiro de Geografia e Estatística) no ano de 2010. Estima-se um total de 1 milhão de pessoas com deficiências físicas (IBGE, 2010) no Brasil. Apesar do número menor de deficientes devido a paralisia cerebral, as limitações impostas por esta condição são extremas, tornando-os completamente dependentes dos adultos, via de rega seus familiares. 


\subsection{Cenário atual}

A acessibilidade para deficientes no Brasil é muito baixa, muitas vezes lanchonetes, hotéis, empresas, shoppings e outros estabelecimentos não possuem infraestrutura de acessibilidade. Quando a infraestrutura existe na maior parte das vezes ela não está dentro das normas brasileiras (BRASIL, 1989 e BRASIL, 1999). Ações de inclusão desse público na sociedade baseiam-se nas normatizações governamentais de universalização dos direitos humanos, sobretudo focadas no respeito à pessoa humana, na proteção, na igualdade e na liberdade; e nos trabalhos assistivos promovidos por instituições que contribuem para o desenvolvimento da personalidade e dos potenciais dos deficientes. A grande maioria destas instituições dispõe de poucas ferramentas assistivas que avaliem e promovam as capacidades cognitivas dos deficientes físicos através de programas de reabilitação. A recuperação das capacidades cognitivas dos deficientes é fundamental para o desenvolvimento de habilidades necessárias a realização de tarefas do dia a dia dentro de casa ou no trabalho.

Deficientes visuais com baixa visão e alguns deficientes físicos com paralisia cerebral ou apenas com idade avançada, precisam de treinamento visual com objetivo de desenvolver as capacidades e promover o desenvolvimento cognitivo (FELICETTI S. e SANTOS E., 2016). Isto é feito, com exercícios que utilizam objetos coloridos de alto contraste e com diferentes texturas. Este método é bastante eficiente visto que combina o uso de diferentes sentidos no processo de cognição e reconhecimento dos objetos, no entanto, não tem muita versatilidade, por ser um processo essencialmente estático. O uso continuado destas ferramentas acaba desestimulando os deficientes devido a monotonia na aplicação. Portanto torna-se necessário a introdução de métodos mais lúdicos e dinâmicos de treinamento cognitivo que mantenham o interesse dos deficientes.

\subsection{Extensão na PUC Campinas}

A Pontifícia Universidade Católica de Campinas (PUC-Campinas) tem como missão produzir, sistematizar e socializar o conhecimento, por meio de atividades de ensino, pesquisa e extensão, visando à capacitação profissional de Excelência, à formação integral da pessoa humana e à contribuição de uma sociedade justa e solidária (PUC-Campinas, 2018). A universidade tem qualificado suas ações extensionistas dando oportunidades aos seus professores de ingressarem num plano de carreira de extensão com 40 horas semanais. Esta realidade implica no envolvimento de parceiros diretos e dezenas de alunos, dos mais variados cursos, permitindo à extensão ser uma atividade rica em aprendizagens significativas. Para os parceiros se privilegia a troca, através de oficinas socioeducativas há intenso enlace entre as demandas da comunidade e o desenvolvimento do projeto, sempre pautado em uma situaçãoproblema.

Nesta troca a Universidade chega aos diferentes lugares da região metropolitana, aprende com eles, interage, apresenta soluções sempre adequadas à realidade vivida e constrói as bases para garantir a autonomia dos envolvidos. A garantia da autonomia é fundamental, pois se entende que a comunidade envolvida precisa conhecer seus desafios, se posicionar diante deles e gerir suas expectativas. Assim, a extensão se refaz num ciclo positivo e interativo; positivo porque todos aprendem, interativo porque é na soma de diferentes conhecimentos que se encontra soluções, às vezes, bem próximas às comunidades e aos seus anseios.

\subsection{Oportunidade/Objetivo}

Descortina-se então uma excelente oportunidade para aplicar as atividades de extensão universitária na promoção do desenvolvimento cognitivo dos deficientes, especialmente aqueles pertencentes às comunidades em fragilidade social, através do desenvolvimento de 
ferramentas lúdicas que despertem o interesse na participação dos programas de reabilitação. Idealizou-se então um plano de trabalho de extensão com objetivo de desenvolver a prova de conceito de uma ferramenta baseada nos conceitos de gamificação que atenda às necessidades e expectativas dos técnicos especialistas das instituições que apoiam o desenvolvimento dos deficientes com relação aos processos de desenvolvimento cognitivo.

A prova de conceito foi desenvolvida segundo o plano de trabalho de aluno de extensão "Dispositivo para treinamento cognitivo", associado ao Plano de Trabalho de Extensão "Engenharia Elétrica e a Inclusão Social/Digital de Deficientes" do prof. Amilton da Costa Lamas. Ela é uma prova de conceito de um dispositivo/ferramenta multissensorial para treinamento cognitivo dos deficientes. Contribui também para a modernização de ferramentas utilizadas pelas instituições para promoção do desenvolvimento da cognição, com a inclusão de sistemas eletrônicos. A promoção do cognitivo avançado e desenvolvimento das aptidões de deficientes é alcançado através de soluções baratas, baseadas em tecnologias de Engenharia Elétrica.

O público-alvo deste trabalho foram os deficientes assistidos e os técnicos especialistas das duas instituições parceiras, o Centro Cultural Louis Braille de Campinas (Braille) e a Therapies Serviços de Fisioterapia e Terapia Ocupacional LTDA (Therapies). Estas instituições têm foco no trabalho assistivo e de recuperação aos deficientes visuais e físicos da região de CampinasSP.

\section{MÉTODO}

\subsection{Parcerias com instituições de apoio}

Os projetos de extensão da PUC-Campinas caracterizam-se por realizarem ações intervencionistas junto à grupos sociais e comunidades organizadas da região metropolitana de Campinas, realizadas através do estabelecimento de parcerias formais com instituições reconhecidas atuantes nas áreas sinérgicas às diretrizes da Pró Reitoria de Extensão e Assuntos Comunitários (PROEXT). O universo destas instituições varia desde privadas até órgãos públicos, organizações não governamentais (ONGs) e organizações da sociedade civil de interesse público (OSCIP). Os resultados descritos neste trabalho são frutos de uma parceria colaborativa com o Centro Cultural Louis Braille de Campinas (Braille) e a Therapies Serviços de Fisioterapia e Terapia Ocupacional LTDA (Therapies). Estas instituições têm foco no trabalho assistivo e de recuperação aos deficientes visuais e físicos da região de Campinas-SP

\subsection{Resumo do método de intervenção social}

O método para a elaboração e construção de uma ferramenta de apoio ao desenvolvimento cognitivo de deficientes baseia-se em três (3) aspectos principais: 1) apropriação de conhecimento; 2) desenvolvimento da prova de conceito; e 3) geração de material cultural. 1) Apropriação de conhecimento: a ideia norteadora desse método é a motivação em colaborar para promover a inclusão social do público alvo através da construção de soluções tecnológicas prezando pela participação direta dos mesmos na problematização das necessidades. 2) Desenvolvimentos da prova de conceito: o desenvolvimento da prova de conceito segue um modelo cíclico, inspirado no Rational Unified Process (RUP), de desenvolvimento de soluções de software fundamentado em requisitos técnicos funcionais e não funcionais obtidos junto ao público alvo. O RUP atualmente é conhecido como IBM Rational Software (IBM, 2019). Os desenvolvimentos foram realizados nos laboratórios da universidade e validados em rodas de conversa específicas. 3) Geração de material cultural: o material cultural desenvolvido consiste em manuais relativos à construção, uso e operação da solução desenvolvida. $\mathrm{O}$ 
principal desafio é escolher uma forma de publicação que seja a mais indicada para o público alvo. Via de regra, quando este público tem alto letramento a forma mais conveniente é a escrita, por outro lado, nas situações de baixo letramento, áudio manuais são bastante recomendados.

Pensado assim, o método configura-se então numa sequência de ciclos dialógicos fundamentados em 3 ações: a) Rodas de Conversa, b) Trabalho Colaborativo e c) Apropriação de Conhecimento. a) Rodas de Conversa - a principal ferramenta para apropriação de conhecimentos, as rodas de conversas se sustentam na necessidade da problematização e de debates acerca de tema comum aos participantes. É neste ponto do ciclo que fica mais evidente a necessidade da superação das diferenças de linguagem, constituindo uma oportunidade ímpar para o desenvolvimento da competência em comunicação plena. b) Trabalho Colaborativo - no momento em que se menciona a expressão "trabalho colaborativo", pressupõe-se uma atividade em que a participação do público alvo do projeto de extensão seja realmente valiosa, isto é, busca-se que esse grupo da sociedade participe dos momentos de decisão, solução, aprimoramento e avaliação do kit. Com isso, cabe aos integrantes vindo de dentro da universidade a sintetização de seus conhecimentos no momento de difundir informações ao público e a tratamento ao recebê-las novamente em prol do objetivo comum. O público alvo, por sua vez, contribui com todo o conhecimento adquirido pela vivência das dificuldades e adaptações realizadas com objetivo de superar as limitações. Este conhecimento não se desenvolve dentro dos muros da universidade. Estabelece-se assim uma via de duas mãos que enriquece o processo educativo dos participantes. c) Apropriação de Conhecimento - nesta ação efetiva-se a parte mais rica do trabalho, quando a universidade retorna à sociedade o investimento recebido. O retorno ocorre na forma de apropriação de conhecimentos, no momento em que a sociedade toma para si os desenvolvimentos, as informações, modelos, planos, propostas etc., os resultados do projeto.

Este método de intervenção social, fundamentado na execução de três modelos: Modelo de Apropriação de Conhecimentos, Modelo de Desenvolvimento da Prova de Conceito e Modelo de Geração do Material Cultural é descrito detalhadamente em Sistema Autônomo para Travessia de Deficientes Visuais em Semáforos de Mário Joaquim de Lemes Neto e Amilton da Costa Lamas (LEMES NETO, 2018). A descrição completa do processo de geração de material cultural pode ser encontrada no artigo "Projeto Final e Extensão - Compartilhando Estratégias e Resultados de Engenharia Elétrica" (FREITAS, 2017).

\section{RESULTADOS E DISCUSSÕES}

\subsection{Requisitos funcionais e não funcionais}

Enquanto os assistidos pela Therapies são essencialmente crianças com paralisia cerebral que não possuem redução significativas de visão, mas que tem severas limitações motoras, o público do Braille é composto de jovens e adultos, inclusive de terceira idade, que possuem baixa visão e consequentes limitações de habilidades físicas, dependendo de como, quando e da gravidade da redução da visão.

Após sucessivas rodadas de conversa com o público alvo concluiu-se que a forma mais apropriada para estimular os deficientes a exercitarem e desenvolverem suas capacidades cognitivas de uma forma lúdica deveria envolver a participação ativa entre eles em um jogo de desafios que lhes fosse familiar. Os requisitos colocados pela equipe de profissionais das instituições parceiras incluíam, mas não se limitavam, a necessidade de estímulos ópticos e táteis versáteis, interatividade livre, de forma que os deficientes colocassem desafios entre si, e programável permitindo que as equipes de profissionais pudessem usar a solução para avaliação do nível deficiência cognitiva e construção de programas de reabilitação. Estipulou-se também 
que a responsividade da prova de conceito deveria indicar, de forma inequívoca, o resultado da ação tomada pelo participante do jogo.

Embora alguns requisitos fossem comuns ou adaptáveis, em alguns casos as necessidades eram antagônicas, enquanto para a Therapies era necessário que a solução não exigisse uma motricidade fina, o Braille gostaria de ter justamente o oposto. O reconhecimento da diversidade de condições de contorno levou a definição de que o jogo deveria ter diferentes características físicas para atender um público com deficiências variadas, mantendo a especificação comum de ser um jogo de tabuleiro, facilmente reconhecível por todos. Consequentemente foram criadas duas versões adequadas ao público de cada uma das instituições parceiras. Após a apresentação da primeira versão física da prova de conceito os técnicos especialistas das instituições parceiras atribuíram o nome de ColorTable.

\subsection{Arquitetura da solução}

A ColorTable consiste em um jogo eletrônico em formato de tabuleiro composto por células (pixels grandes) com intensidade luminosa e cores individualmente ajustáveis que permite a definição de uma sequência livre ou programável de estímulos visuais. O princípio básico consiste na repetição de uma sequência arbitrária ou programável, seguido de uma resposta audível correspondente ao estado final da ação, indicando o acerto ou não, bem como sinalizando a finalização da sequência. A repetição é identificada através do acionamento de um sensor acoplado ao "pixel" correspondente.

A Figura 1, apresenta um esquema da arquitetura da solução. A ColorTable é composta por uma CPU (Arduino) conectada a um Módulo de Apresentação, outro de Controle e a um Módulo de Alimentação. A CPU contém toda a lógica de programação, inserida através da porta de entrada (P) e é encarregada de receber a informação dos sensores $(\mathbf{S})$, assim interpretando qual a resposta do usuário e checando se a resposta está "certa" ou "errada" para então sinalizar de forma audível a escolha. O Módulo Apresentação é composto de um tabuleiro constituído por 15 "pixels", cada um deles com 2 LEDs endereçáveis, tendo assim 30 LEDs. Esta é a área de jogo, onde os participantes exercitam as sequências luminosas. O Módulo de Controle, com o uso de botões (B1 - B4), permite a definição o tipo de uso, se livre ou programado, a inserção da correspondente programação na CPU, bem como permite a definição das intensidades luminosas e das cores de cada um dos "pixels" do Módulo de Apresentação. A COLORTABLE possui um Módulo de Alimentação recarregável para suprir as necessidades de corrente e tensão de alimentação da CPU e dos 30 LEDs endereçáveis do Módulo de Apresentação.

Figura 1 - Arquitetura esquemática da ColorTable 


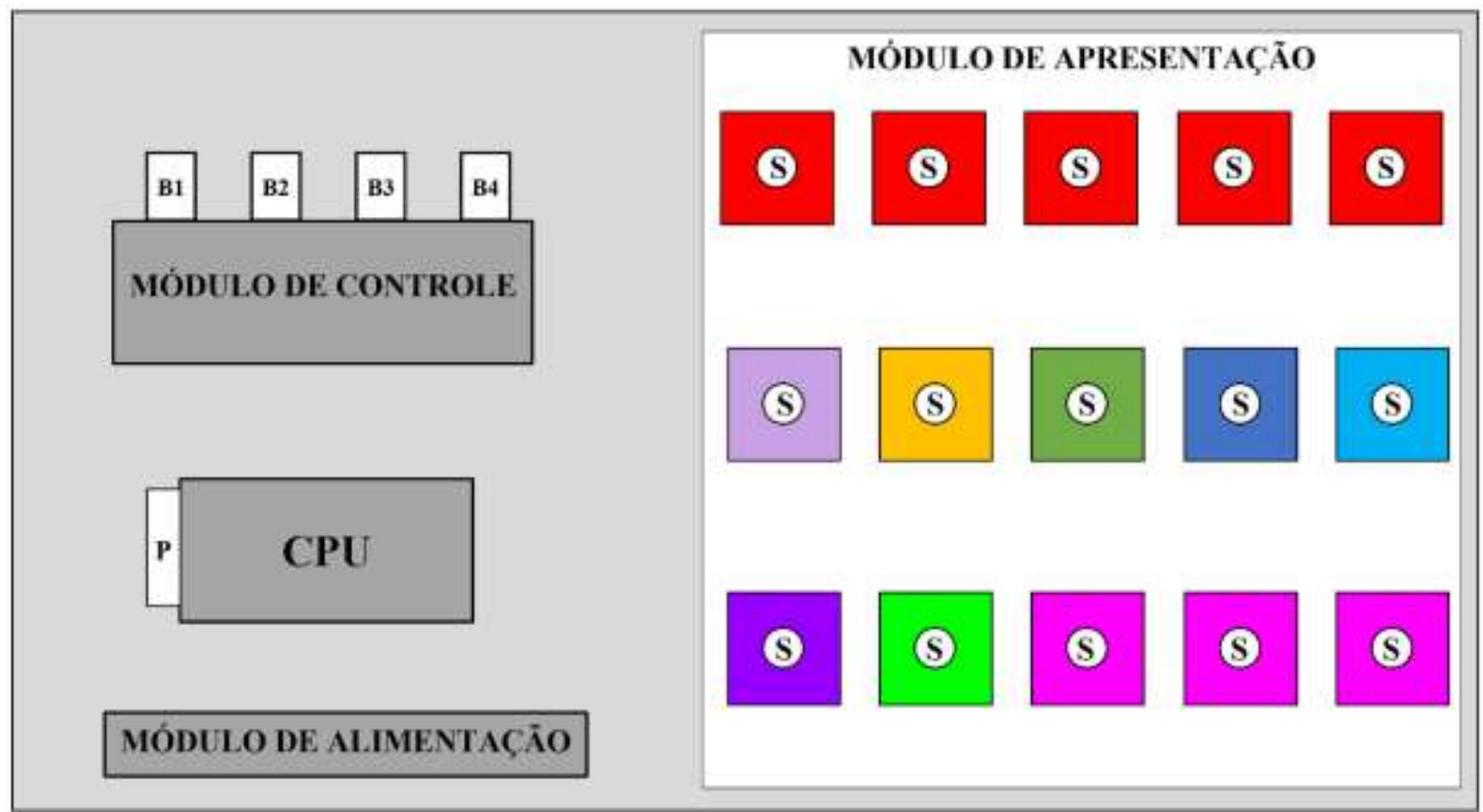

Fonte: Autores

\subsection{Programa de Desenvolvimento Cognitivo}

Programas de desenvolvimento cognitivo utilizando a ColorTable consistem em definir e depois repetir uma sequência (posição) de cores até ocorrer em erro, escolhendo uma cor fora de posição. Eles podem ser executados de três (3) formas: 1) modo livre - neste caso a prova de conceito é usada pelo deficiente, assistido pelo operador onde este inicia a sequência e o deficiente procura repetir a sequência gerada aleatoriamente na CPU observando as cores e a posição do "pixel" no tabuleiro; 2) modo programado - neste modo o operador carrega uma sequência na CPU utilizando uma porta de entrada e deficiente segue a sequência de cores e posição pré-estabelecida; 3) modo treinamento - no caso do treinamento o operador define apenas a sequência de cores e todos os "pixels" acenderão simultaneamente naquela cor, assim o deficiente é estimulado a identificar a cor ou sequência de cores definida.

\subsection{Preparação e programação da ColorTable}

Antes de iniciar qualquer atividade com a prova de conceito é necessário programar as cores que acenderão em cada "pixel". A programação é feita através dos botões do módulo de controle que permite a atribuição de qualquer cor a cada "pixel" ajustando as componentes RGB (Red, Green, Blue) de cada LED endereçável individualmente.

No caso de modo livre o jogo está pronto para iniciar, visto que a sequência das luzes é definida pelo jogador que inicia a partida. Quando a prova de conceito for usada no modo programado é necessário que a programação da sequência e das cores de cada "pixel" seja inserida na CPU. Isto é feito através de linhas de comando externas utilizando um computador para carregar as linhas de código específicas nos pontos de programação pré-definidos. Uma vez preparada a programação esta é transferida para a CPU conectando o computador à porta específica de programação.

Os manuais de programação, uso, operação e construção, entregues para as instituições parceiras, descrevem detalhadamente os passos necessários para a realização de cada um dos processos. 


\subsection{Material Cultural}

Um dos principais objetivos do programa de extensão da PUC Campinas é a devolutiva para a sociedade do investimento realizado na instituição. Neste caso a devolutiva é feita através da apropriação dos conhecimentos, métodos e processos desenvolvidos durante o projeto. Especificamente as instituições parceiras recebem treinamento na operação da prova de conceito e todos os manuais necessários para a replicação, manutenção, operação e desenvolvimento de programas de treinamento, avaliação e reabilitação cognitiva de seus assistidos. São repassados também todas as listagens e programas de software necessários para a construção de programas de de desenvolvimento cognitivo.

\subsection{Demonstração da prova de conceito}

Após a realização de múltiplos ciclos dialógicos com as instituições parceiras foi concretizada uma prova de conceito da ferramenta de apoio ao desenvolvimento cognitivo de deficientes que atende aos requisitos definidos colaborativamente. As imagens apresentam a área correspondente ao Módulo de Apresentação com os "pixels" iluminados em 3 cores distintas. O botão no centro de cada "pixel" sinaliza à CPU a escolha do usuário quando pressionado. A Imagem 1 ilustra o uso das cores no Módulo de Apresentação.

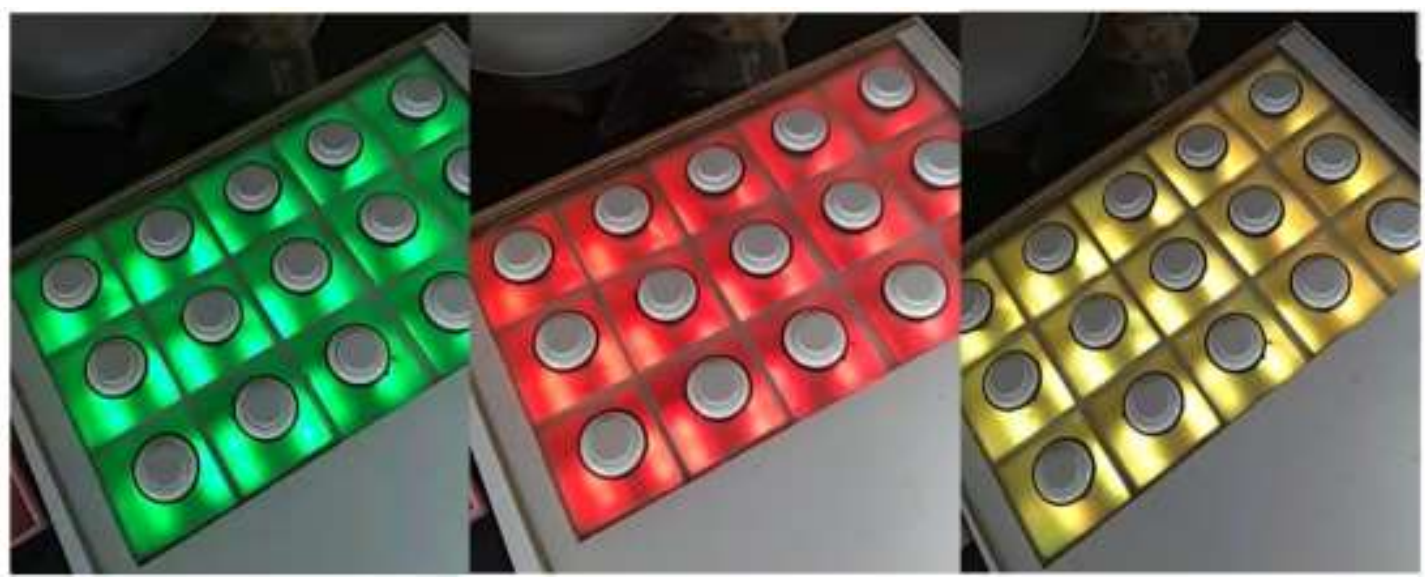

Fonte: Autores

Após o último ciclo das rodas de conversa a prova de conceito foi validada pelos técnicos das instituições parceiras e demonstrada no evento de encerramento do projeto. A Imagem 2 apresenta o uso da ColorTable durante o evento de encerramento do projeto no Centro Braille.

Visando contemplar as diferenças entre os requisitos apontados pelas intuições desenvolveu-se um segundo modelo da prova de conceito em que os botões grandes foram substituídos por menores. Isto se deu porque o Centro Braille optou por desenvolver a motricidade fina em seus assistidos, enquanto que os assistidos pela Therapies não prioridade alguma neste desenvolvimento.

\subsection{Impacto na formação do discente}

A participação no projeto de extensão permitiu ao discente identificar, projetar e analisar sistemas, produtos e processos na área de Engenharia Elétrica/Mecânica, exercitando a formulação e solução de problemas de engenharia. A participação também promoveu a 
aplicação dos conhecimentos de software e hardware, no desenvolvimento de sistemas informatizados, o desenvolvimento dos princípios éticos que orientam a conduta profissional do engenheiro e a exploração da aplicabilidade de soluções no mundo das pessoas com mobilidade prejudicada; da mesma forma oportunizou a análise crítica da construção do ser humano, permitindo a vivência de desafios contemporâneos articulando abordagens relativas a questões de direitos humanos do multiculturalismo, da identidade e das relações étnico-raciais.

À medida em que as habilidades de engenharia se tornam uma commodity, os programas de Engenharia Elétrica/Mecânica são instados a adaptar suas estratégias pedagógicas com objetivo de melhor preparar seus graduados. Espera-se que os engenheiros do século XXI tenham uma base técnica forte, ao mesmo tempo em que sejam capazes de trabalhar com pessoas com diferentes tipos de capitais intelectuais e sociais e ter um alto nível de flexibilidade cognitiva. Neste projeto o discente participante realizou atividades de extensão simultaneamente com as classes regulares. Neste caso, as atividades dizem respeito ao coplanejamento e co-criação/execução de serviços e/ou aplicações, soluções, provas de conceito, protótipos, inovadores fundamentados em tecnologias desenvolvidas nas disciplinas do curso, num formato colaborativo entre estudantes de engenharia elétrica, técnicos sociais e assistidos. O estudante, participante do projeto, tem a oportunidade de desenvolver suas habilidades de comunicação, análise e interpretação de dados, vivências relacionamentos de forma não disponível na sala de aula. Ele também experimentou resolver situações de conflito e encontrar usos criativos e aplicações para o conhecimento não previstos dentre os muros da universidade. Através desta experiência, o graduando de engenharia desenvolveu um sentido maior de responsabilidade com a sociedade e uma melhor compreensão do que significa ser um engenheiro. A participação no Projeto de Extensão também trouxe várias oportunidades de reconhecimento profissional pelos técnicos e pelos assistidos, o que estimulou o aluno a alcançar um melhor desempenho no curso.

Imagem 2 - Imagem durante o evento de encerramento do projeto no Centro Braille

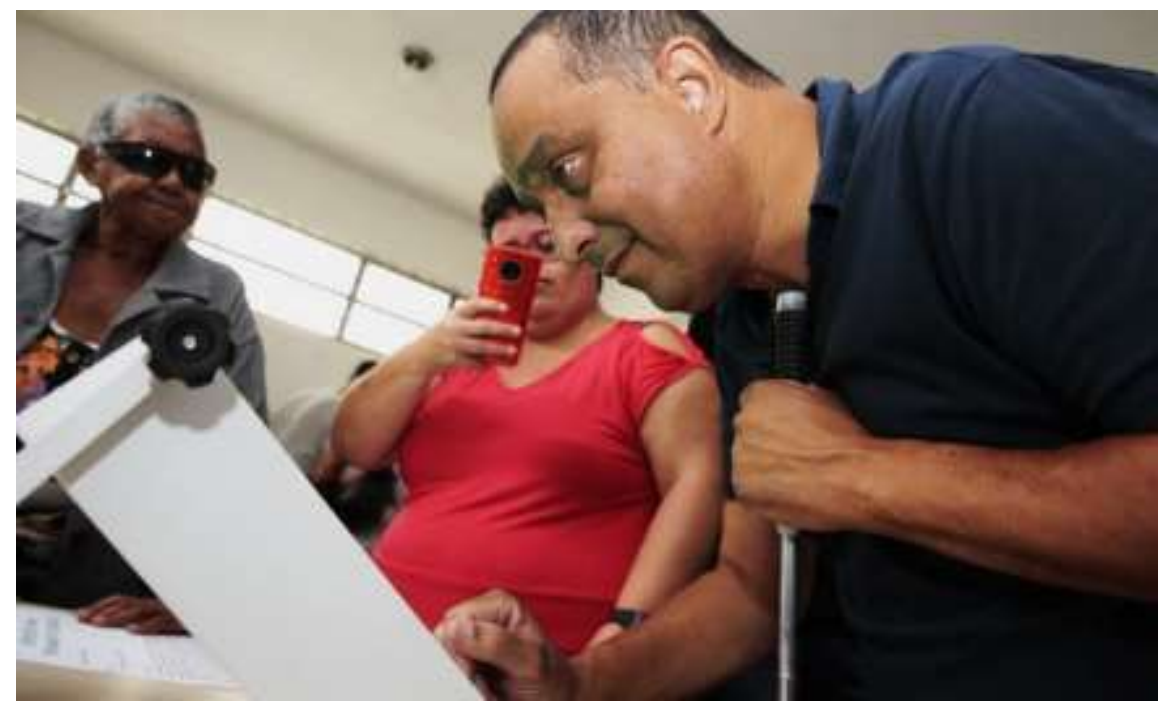

Fonte: Autores 


\section{CONSIDERAÇÕES FINAIS}

Neste artigo apresentou-se a ideação e a construção/validação de uma prova de conceito de uma ferramenta de apoio ao desenvolvimento cognitivo de deficientes baseada em estímulos visuais com ampla variedade e controle de cores. Possuindo três modos de operação a ferramenta, nomeada ColorTable pelos deficientes, permite o uso individual ou em duplas, num formato livre ou programável.

O desenvolvimento colaborativo, típico de projetos de extensão, permitiu que as ideias dos técnicos especializados e dos próprios deficientes fossem incluídas no resultado final, seja na forma de requisitos funcionais ou não funcionais. A ferramenta utiliza conceitos de gamificação, o que torna o desenvolvimento das capacidades cognitivas e os testes de avaliação lúdicos e prazerosos de serem realizados.

As instituições parceiras se mostraram bastante motivadas por terem incorporado em seus acervos de ferramentas uma solução simples que apoia o desenvolvimento e avaliação cognitiva de deficiente construída especificamente para as suas necessidades. Esta é uma consequência natural do desenvolvimento colaborativo

\section{Agradecimentos}

Os autores agradecem o suporte da Pró-Reitoria de Extensão e Assuntos Comunitários (PROEXT) da PUC-Campinas; das instituições parceiras deste projeto de extensão, o Centro Cultural Louis Braille de Campinas (CCBLC) e a Therapies Serviços de Fisioterapia e Terapia Ocupacional LTDA (Therapies); dos especialistas da área de saúde e educação das instituições parceiras, na pessoa da Fabiana Pazinatti (pedagoga), da Juliana Nicomedes (Terapeuta Ocupacional) e da Alessandra Montoan (Terapeuta Ocupacional); dos colaboradores dos laboratórios de Eletrônica e Meios de Comunicação e da Maquetaria da PUC-Campinas.

\section{REFERÊNCIAS}

BRASIL. Decreto-Lei no 3.298, de 20 de dezembro de 1999. Disponível em: http://www.planalto.gov.br/ccivil_03/decreto/d3298.htm . Acesso em: 05 mai. 2020.

BRASIL. Lei $\mathbf{n}^{\mathbf{0}} \mathbf{7 . 8 5 3}$, de 24 de outubro de 1989. Dispõe sobre o apoio às pessoas portadoras de deficiência, sua integração social, sobre a Coordenadoria Nacional para Integração da Pessoa Portadora de Deficiência - Corde, institui a tutela jurisdicional de interesses coletivos ou difusos dessas pessoas, disciplina a atuação do Ministério Público, define crimes, e dá outras providências. Disponível em:

http://www.planalto.gov.br/ccivil_03/leis/L7853.htm . Acesso em: 05 mai. 2020.

FREITAS, D. E. et ali, Projeto Final e Extensão - Compartilhando Estratégias e

Resultados de Engenharia Elétrica - Anais do $45^{\circ}$ Congresso Brasileiro de Educação em Engenharia - COBENGE 2017. Disponível em:

http://www.abenge.org.br/sis_artigos.php . Acesso em: 05 mai. 2020.

FELICETTI, S e SANTOS, E. Tecnologias assistivas, cegueira, baixa visão, paralisia cerebral: uma revisão da literatura. Revista Tecnologia e Sociedade, v12, n.24, p. 1-29, 2016. 
IBGE - Censo Demográfico, Características gerais da população, religião e pessoas com deficiência. Rio de Janeiro, p.1-215, 2010. Disponível em:

https://biblioteca.ibge.gov.br/visualizacao/periodicos/94/cd_2010_religiao_deficiencia.pdf . Acesso em: 02 jun. 2020.

IBM. Rational Software, 2014. Disponível em:

https://www01.ibm.com/software/br/rational/ . Acesso em: 03 mai. 2020.

LEMES NETO, Mário Joaquim, LAMAS, Amilton da Costa 2018 - Sistema Autônomo para Travessia de Deficientes Visuais em Semáforos, VI Jornada de Extensión Universitária del Mercosur, 2018, Tandil. 24-27 de abril 2018 ISBN: 978-950-658-448-1. Disponível em: http://extension.unicen.edu.ar/jem/Libro_JEM_2018.pdf - página 40. Argentina, 2018. Acesso em: 23 mai. 2020.

\title{
A TOOL FOR HANDICAPPED COGNITIVE DEVELOPMENT
}

\begin{abstract}
Autonomous mobility development of handicapped or visually impaired people requires cognitive training to achieve a safe level of performance. In this paper, we report the idealization, construction, and validation of a proof of concept designed to promote such developments. The work was performed in a collaborative method with two social institutions, named Centro Cultural Louis Braille de Campinas e a Therapies Serviços de Fisioterapia, whose goal is to support and rehabilitate the handicapped. The final version oh the proof of concept was named ColorTable by the target audience of these institutions. It consists of a game table with 15 large pixels like regions that can be illuminated by selected addressable RGB LEDs. A large variety of rehabilitation programs and handicap assessment routines can be designed and implemented. The collaborative development process assures that results are properly designed for the target population.
\end{abstract}

Key-words: cerebral palsy, cognitive development, collaborative method, handicapped people, university extension project. 